\title{
THE EFFECTIVENESS OF A PROPOSED PROGRAM FOR MUSICAL ACTIVITIES TO SPREAD THE VALUE OF TOLERANCE AMONG SOME CHILDREN OF THE FIRST STAGE OF BASIC EDUCATION
}

\author{
Noura Osama AL-LAITHI*
}

Faculty of Music Education, Helwan University, Egypt

\begin{abstract}
The researches covered various topics examining the various aspects of sadness and unhappiness in human life, as well as dealing with the bright side in their lives such as feeling happiness, joy and tolerance, the necessity of optimism, hope, and satisfaction with aspects of life and enjoyment of it or some of it, as well as patience and steadfastness as well as the positive aspects in a person's relationship with his brother man, his family and friends And the external reality around him to create a state of adaptation, suitability, harmony, self-harmony and social support, to make the human being more positive and effective. The importance of tolerance stems from being a moral virtue and a fundamental issue in our current political, social and cultural life, because people today are in greater need for effective tolerance and positive coexistence between people more than ever before due to the rapprochement between cultures and interaction between civilizations that increases day after day thanks to the information and communication revolution.

Keywords

Effectiveness, Musical Activities, Spread, The Value of Tolerance, Children, Basic Education.
\end{abstract}

\section{Introduction}

The technological revolution that removed temporal and spatial barriers between nations and peoples until everyone became living in a large global village. Therefore, there is no alternative to spreading the culture of values and spreading the culture of values, tolerance and brotherhood among nations and peoples, as well as among family members wherever they are and whatever the diversity and difference between them, as diversity is one of the laws of God in his creation, so the values of truth, goodness, justice and peace must be resurrected.

Since the supreme goal of education is to prepare the child for the child to become a good citizen, all academic subjects derive their objectives from education in general, but differ in their means depending on the nature of their formation, as musical activities are presented to the child in order to practice them and interact with them and thus acquire the skills and behaviors that are to be learned in an easy way. Musical activities present many values and principles, such as the value of tolerance and acceptance of the other, as the issue of cultivating tolerance values through education is essential and possible and can be achieved through a system of educational initiatives that are based on teaching the young people the values of tolerance and the human sense of acceptance of the other and spreading loyalty, belonging, love of the homeland and the spirit of work The seriousness and their adherence to a culture of

\footnotetext{
* Corresponding author: info@music.helwan.edu.eg
} 
moderation and moderation away from extremism, violence and destructive ideas and their remoteness from the ideology of terrorism and hatred of others, as part of the implementation of serious processes related to the introduction of tolerance values in education. It is necessary to develop clear plans based on various artistic activities that can be implemented to instill the values of tolerance and feminine sense of love. , The researcher believes that when a person has the capacity of tolerance, he can get rid of all psychological and social damages and time Sadia and health, which may affect his life negatively and those around him in society, despite the importance of tolerance in human life and we find that there is little interest in it by educators, which made the researcher think about preparing a program based on some musical activities to spread the values of tolerance among some children of the stage Initial from basic education

\section{Research Problem}

Through the researcher conducting an exploratory study of (5) public schools in the western region of Cairo, five schools were carried out, where a referendum was applied to a number of social supervisors in those schools on the spread of tolerance values among children or their lack thereof, as the results of the exploratory study indicated the number of their presence to a degree of $85 \%$ Thus, the research problem was identified in the deficiency of the principle of tolerance for some children of the first stage of basic education, which prompted the researcher to prepare a program for some musical activities to spread the values of tolerance among some children of the first stage of basic education.

\section{Previous studies on the topic:}

The first study: The effect of musical activities in evaluating some aspects of the unwanted emotional development of a child deprived of a family: This study aimed to evaluate some of the unwanted emotions of the deprived child in the family, namely (aggression and fears), and that evaluation of these emotions through the application of a program based on different musical activities. Ranging from 4 to 6 years, the results of the research resulted in an evaluation of emotional aggression and fear among these children.

The second study: "The effect of the kinetic musical story on the development of some positive behavioral patterns in a pre-school child" A comparative study between normal and mentally handicapped children: This study aimed at developing the child's social values through musical activities through the application of a music program. It also aimed at developing some behavioral patterns for pre-school children, which were identified in the system (honesty - helping the needy - hygiene) by providing them with them through a proposed program based on Kinetic Musical Story. The study followed the experimental 
method with one group on a sample consisting of two classes in ordinary kindergartens at Lycee El Horreya School in Heliopolis and the mentally handicapped in the School of Intellectual Education east of Nasr City. The researcher concluded that the program she applied had an effective effect on developing positive behavior for the children of the research sample.

The third study: "The effectiveness of a proposed program of musical activities to improve some emotional aspects of the family deprived child:"

This study aimed to reduce the severity of aggression (verbal and material - direct and indirect) of the deprived child of a family and deposited in one of the housing institutions in Alexandria Governorate. Musical, which included some social, national, religious and moral values.

The fourth study: "The effectiveness of a proposed program that uses music in reducing behavioral disorders in street children."

The fifth study: "The effectiveness of the musical activities program to improve some emotional aspects of the kindergarten child."

This study aimed to employ group or individual musical activities to reduce aggression and introversion in the kindergarten child. This study followed the experimental approach, through the proposed musical program, and the results resulted in improving the emotional aspects of the kindergarten child.

The sixth study: (Tolerance and revenge and their relationship to personality traits among a sample of university students): This study aimed to identify the nature of the relationship between tolerance and revenge and personality traits among university students, and through a program based on their use of the tolerance scale, the revenge scale, and the five major factors of personality. The results indicated the existence of a statistically significant negative association between tolerance and revenge, as well as positive statistically significant correlations between tolerance and both extroversion, acceptability, conscientiousness, and openness to experience.

\section{General comment on previous studies related to the research topic:}

- There are many studies that have focused on developing the positive behavior of the child with musical activities, such as the study of Sahar Muhammad Al Shaarawy 2007, which is consistent with the current research topic. The previous research samples were a mixture of normal children, which is consistent with the current research sample, while the third study used the 2017 magic study, a sample of mentally disabled children, which differs from the current research sample.

\section{Return from previous studies related to research:}

The researcher benefited from reviewing previous studies related to: 
1- Ensuring the effectiveness of musical activities in improving children's behavioral patterns and different values.

2- Knowing the steps for preparing educational programs.

3- Learn about some innovative exercises by researchers aimed at improving children's behavior.

4- The statistical equations used to arrive at and interpret the research results

\section{Second: theoretical concepts}

\section{A- Musical activities:}

Musical activities are represented in listening and tasting, singing, musical games, the kinetic musical story, and playing the instruments of the rhythmic band, as these activities are concerned with the child's enjoyment of life and emotional ventilation of what is inside him, so he escapes from his behavior, as the musician is of a projective nature in which the child falls into his emotional struggles.

1- Listening and tasting: Musical listening is a training of the ear to receive the sound stimuli and select and distinguish between the components of the musical work. As for the taste, it is the educational training that aims to realize the aesthetic values in the music through the ability to seriously listen with the awareness and understanding of the components of the music, and taste in its reality It includes all kinds of musical activities, as each of its branches aims to expand the circle of information and deepen its concept of art.

2- Singing: Singing is one of the activities rich in different experiences that help the child to develop various aspects of his personality, whether they are physical, mental, emotional, social and emotional aspects. Singing is an integrated musical activity that combines the word and the musical content of rhythm and melody, and singing songs allows the child to breathe correctly and pronounce Correctly for clear exits of expressions, which brings the child to an increase in his vocabulary, in addition to acquiring many positive behaviors by understanding the meanings of their words

3- Musical games: educators in general and musicians in particular have taken advantage of the connection between the child and play, to teach him many abstract educational concepts, whether these concepts are related to the physical aspect of acquiring muscle skills, or to the emotional aspect to develop the ability to control emotions, or to the psychological aspect to discipline behavior, Or it is concerned with the mental aspect to develop belonging, focus and innovation, or it is specialized in the artistic aspect to develop a sense of the elements of music, or it is specialized in the aesthetic aspect to give the meaning of balance, harmony and harmony. Emile Jacques Dalcroose, Carl Orff, and Aisha Sabri agree. And Omaima Amin on the 
educational principle (learning by playing) and therefore we find them all interested in musical games.

4- The Kinetic Musical Story: The story is one of the important educational media that can be used in different stages of education, especially in childhood. This is due to the special attraction of the story that is included in its composition. Sentimentality pushes him to merge with it to reach the end.

\section{B- Tolerance value:}

- Its definition: Tolerance is overcoming the mistakes of others and facing offense with charity, forgiveness and love of goodness, and words and actions must be identical in tolerance to achieve the true meaning of it. Some may utter tolerance with their words, but their heart is full of hatred and hatred for the offended person, and this does not apply to the concept of tolerance because tolerance must be out of the heart before saying it and that appears from actions. Usually, when a person receives the abuse, revenge and responding to this abuse in the same way is the first thing that comes to his mind, so forgiveness is considered one of the morals that need sincere belief.

\section{The importance of tolerance:}

1- Contributing to implanting love in the souls of the members of society.

2- Contributing to getting rid of the problems that result from the accumulation of attitudes among individuals. Maintaining the individual's health and psychological well-being.

3- Improving the individual's ability to self-control and train them not to be emotional, nervous and think negatively.

4- Motivating the individual to have a positive, cheerful personality and more busy with his own development and development to meet his ambitions.

5- Winning the love and appreciation of others; Because the forgiving person pardons the mistakes and mistakes that may happen unintentionally.

\section{Results:}

- The experiment was conducted on a sample of fourth-grade children (10 children), where the pre-post test was applied to diagnose tolerance) prepared by / Lily Choucair for the experimental group, and then the researcher applied the post test (tolerance diagnosis) in order to obtain the averages between the two tests.

- The researcher applied the pre-post test on the fourth grade children (the research sample was (10 children).

- The researcher conducted the statistical treatment between the mean scores of the children and the achievement pre-post test. 


\section{Recommendations}

1- Preparing workshops and conducting training courses for parents to spread the values of tolerance among children.

2- Introducing the value of tolerance within the curricula of the Ministry of Education and urging the importance of the value of tolerance for children.

\section{References}

1- Amira Sayed Farag and Others: Musical Activities between Theory and Practice - Third Edition - Cairo - 2001.

2- Rehab Mahrous Mahmoud Ali, an unpublished master's thesis, Girls' College - Ain Shams University - 2007.

3- Sahar Muhammad Al-Shaarawy, unpublished PhD thesis, Faculty of Women - Ain Shams University - 2007.

4- Attiyat Saqr: The Effectiveness of the Musical Activities Program to Improve Some Emotional Aspects of Kindergarten Children, Master Thesis, Unpublished, Faculty of Music Education, Helwan University, 2004.

5- Fouad Abu Hatab - Amal Sadeq, the psychology of growth, third edition, Cairo, 2001.

6- Camellia Jamal El-Din: The Effectiveness of a Proposed Program Using Music in Reducing the Behavioral Strikes of Street Children, Individual Research, Journal of Sciences and Arts, College of Music Education, Helwan University.

7- Muhammad Abd al-Rahman Abdullah Qasim - Unpublished MA - Faculty of Music Education - Helwan University, 2005.

8- Noura bint Saad Al-Buqami: Tolerance and revenge and their relationship to personality traits among a sample of university students, published research, Imam Muhammad bin Saud Islamic University, Riyadh, Saudi Arabia - 2017.

9- Muhammad Abd al-Rahman Abdullah Qasim - Unpublished Masters Degree - Faculty of Music Education - Helwan University, 2005.

10- Najwa Shukry Muhammad MOAMEN, Doaa Muhammad ABBOUD, "SEA INSPIRATION" COLLECTION INNOVATIVE DRESS- FORM DESIGNS INSPIRED BY THE MARINE ENVIRONMENT USING SHELLS, International Journal of Humanities and Language Research, Vol. 2, No. 1, 2019, pp. 15-19. 